\title{
Noise Annoyance Due to Wind Flow Interaction with a Building's Facade
}

\author{
Marcos Raul Lisboa, José Cataldo Ottieri, Alice Elizabeth González \\ IMFIA, Faculty of Engineering, University of the Republic, Montevideo, Uruguay \\ Email: mlisboa@fing.edu.uy, jcataldo@fing.edu.uy, elizabet@fing.edu.uy
}

Received 15 January 2015; accepted 3 March 2015; published 5 March 2015

Copyright (C) 2015 by authors and Scientific Research Publishing Inc.

This work is licensed under the Creative Commons Attribution International License (CC BY). http://creativecommons.org/licenses/by/4.0/

c) (i) Open Access

\begin{abstract}
The analysis of acoustic emissions generated by the interaction between the wind and a building's facade of approximately $90 \mathrm{~m}$ high, located in the city of Montevideo, is presented. There is a helipad on the roof of the building. It is surrounded by a perforated plate $(4.87 \mathrm{~m}$ high). Once the building was finished, complaints about the noise annoyance were expressed by some neighbors and working population in the building. Measurements of sound pressure levels on the site have been done. Also the possible acoustic sources were physically characterized. The noise source was identified: the acoustical emissions were associated with a phenomenon caused by wind speeds above $20 \mathrm{~m} / \mathrm{s}$ from different directions, generating high sounds pressure levels in octave band of $4000 \mathrm{~Hz}$, after its passage through the perforated plate on the contour of the roof. These studies were complemented by measurements in wind tunnel using a physical model built with the same plate installed in the building, which allowed verifying the results.
\end{abstract}

\section{Keywords}

Noise Annoyance, Wind, Building, Perforated Plate

\section{Introduction}

The sound results from a propagation of an oscillatory movement of particles through a material medium, which has associated an oscillatory field of pressures. Such movement and oscillatory field of pressures can be associated to different processes such as vibration of a solid surface, implosion or explosion of steam bubbles or oscillations of flow due to the occurrence of instabilities, among others. Once the oscillatory field is produced, the resulting propagation velocity will be characteristic of the medium in which it is developed, known as speed of sound. The sound produced is then characterized by frequency and amplitude of oscillatory motion.

The aforementioned sound wave is associated to a flow of power per unit area that surrounds the site where 
the source generates such movement. Integrating the power flow on a surface surrounding, the issuer is possible to estimate the emitted power, which is often expressed as power level in decibels (dB).

This paper presents the analysis of acoustic emissions generated by the interaction between the wind and the facade of a building. Indeed, according to the complaints of the people living and/or working in the area around the building, the occurrence of certain weather events generated noise emissions with such intensity to be heard; they may result in a potential cause of discomfort or annoyance, constituting the events of interest.

Consequently, a physical characterization of possible sound sources in the building was made. The sound production process was physically described, and its frequency and intensity were estimated. In addition, a set of measurements were developed to characterize the sound that was registered in areas of interest of the building, particularly on the roof of it. The results were verified by wind tunnel tests of the faculty of engineering. Finally, a diagnosis was made and mitigation actions were proposed.

\section{Characteristics of the Noise Source}

\subsection{Building Description}

The tower under study is part of a special architectural complex that comprises several buildings with similar characteristics. The site where the tower is located is presented at different scales in Figure 1.

In Figure 1(d), the building under consideration is indicated by the star. Also, a building $120 \mathrm{~m}$ high that is located between the SOUTHWEST and SOUTH-SOUTHWEST directions relative to it indicated by a circle.

The building under study, Figure 2(a), is something more than $88 \mathrm{~m}$ high. The floor of the roof is placed at $81 \mathrm{~m}$ over the ground; it is surrounded by a parapet built of masonry $1.6 \mathrm{~m}$ high. Over it, an open window of $0.82 \mathrm{~m}$ over the top edge of the guardrail is defined all along the perimeter, just to the lower edge of a perforated metal plate $4.87 \mathrm{~m}$ high, that is supported by vertical tubes. A helipad is located at the center of the roof [1].

The plate at the top of the building is a plate of Aluzinc $0.5 \mathrm{~mm}$ thick. It has four segments on each face, Figure 2(b): two of them are $5.24 \mathrm{~m}$ wide and the others are $6.26 \mathrm{~m}$ wide; all of them are $4.87 \mathrm{~m}$ high. It has horizontal folds every $4 \mathrm{~cm}$, conferring to it a trapezoidal appearance as shown in Figure 2(c). The supports are vertical tubes of rectangular cross-section of $50 \mathrm{~mm}$ by $100 \mathrm{~mm}$ and $4.87 \mathrm{~m}$ high.

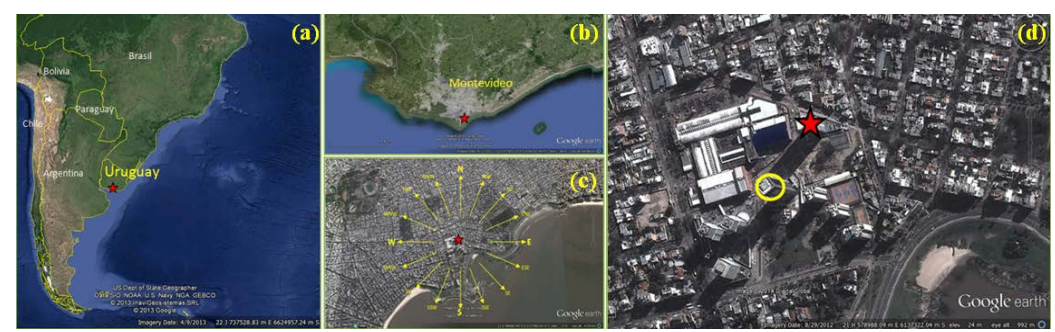

Figure 1. Location of the study site, on a continental scale (a); Department-wide Montevideo (b); City, where the location according to the cardinal points (c) is included; and (d), in the building complex (images modified from Google Earth).

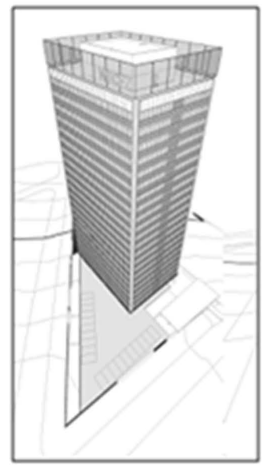

(a)

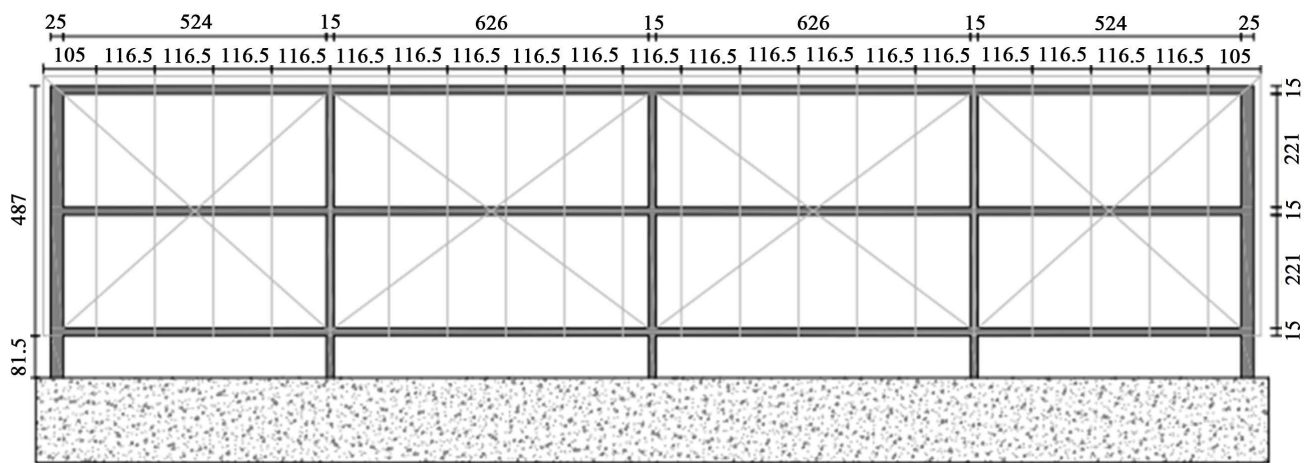

(b)

Figure 2. (a) Sketch of the building under study. Elevation of a plate; (b) Front view; (c) Court (reproduced from [1]). 
The plate is a perforated plate with circular holes arranged in rows. The diameter of the holes is $2.5 \mathrm{~mm}$, the gap between holes in each row is $5 \mathrm{~mm}$ and the spacing between rows is also $5 \mathrm{~mm}$.

Two cooling towers of the air conditioning system are installed on the roof, in the free space around the heliport, as well as pumps and fans associated with their operation. Also, some impulses in the area of the ventilation system are identified. Some other discharges of the ventilation system are located close to the level of the street.

\subsection{Possible Sources of Acoustic Emissions}

Many building sites where potentially annoying acoustic emissions may occur were identified. They are presented and discussed on next sections.

\section{Flow around the structure}

The interaction between air flow and a structure can result on vortex shedding with a scale similar to dimensions of the structure [2]. These vortexes are emitted with a characteristic frequency, depending on the geometry of the obstacle and that is directly related to the velocity of the incident flow over the obstacle. A fluctuating pressure field results, and an acoustic emission is induced.

If $D$ is the width of the obstacle, $U$ is the mean value of the incoming wind speed and $f$ is the vortex shedding frequency, the Strouhal number is set to [3]-[5] as:

$$
S t=\frac{f \cdot D}{U}
$$

In this case, this parameter has a value of about 0.12 for the building [6]. Taking into account that the width of the building is $23 \mathrm{~m}$, the emission frequency of vortices for a wind speed of $20 \mathrm{~m} / \mathrm{s}$ would be less than $1 \mathrm{~Hz}$. Lower wind speeds also lead to lower frequencies.

\section{Acoustic emissions in support tubes}

If conditions are established for a fluctuating flow to occur inside the tubes that support the perforated plate, e.g. a speed change of the wind that slips around the pipes, these tubes can become noise sources. Depending on the boundary conditions, e.g. an open end and a closed one, the induced sound wave becomes stationary and it remains moving inside the tube.

The frequency of the wave depends on the length of the tube and on the speed of the waves. For ideal gases, as it can be assumed that the air behaves in this case, this speed is temperature dependent.

The frequency of pressure waves and their velocity were determined from the analysis of non-stationary flow inside a tube [7], for air temperature of $15^{\circ} \mathrm{C}$. The frequency was found to be about $35 \mathrm{~Hz}$.

\section{Vibration of the perforated plate}

The air flow around the plates results turbulent. Then a fluctuating load onto the shields presents a non-stationary response and therefore a vibration is induced on them by the same wind action.

To characterize the effects of turbulent wind velocity component, $v^{\prime}$ turbulence intensity $I$ as used:

$$
I=\frac{\sqrt{\left\langle v^{\prime 2}\right\rangle}}{U}
$$

At the height of the plate where the shed is located turbulence intensity would be 0.25 .

In particular, the fluctuating components of velocity having a frequency corresponding to the first normal mode of vibration of the plate are very significance. To calculate the frequency of that mode, each shield was examined as a set of homogeneous bar recessed or projecting both ends as appropriate. Each bar or shield portion between consecutive supports, has a mass of approximately $11.5 \mathrm{~kg}$, being the modulus of elasticity of 72 GPa. The frequency of the first vibration mode of the shield portion at both ends embedded would be $117 \mathrm{~Hz}$, while the cantilever frequency of the present a first normal mode of $177 \mathrm{~Hz}$. Anyway this frequency induces a fluctuating pressure field and therefore the acoustic signal output.

On the roof, the movement of each leg shield induces a level of sound pressure of the order of $38 \mathrm{dBZ}$. Since total would be about 80 sections of sheet metal and assuming all sections emit sound, the sound pressure level on the floor of the roof of the building-if there was no obstacle to propagation- would be of the order of 44 $\mathrm{dBZ}$ in while scale A would be approximately $33 \mathrm{dBA}$. 


\section{Flow through the holes}

When the wind flows around the building is set up a pressure field on its envelope ${ }^{1}$. If $P$ is the gauge pressure at a point of the shell and $U$ is the mean wind speed at the height of the building, the pressure coefficient according to the following expression is defined [4]:

$$
C_{p}=\frac{P}{\frac{1}{2} \rho U^{2}}
$$

The pressure differences which are set up on the sides of the building generate a flow through the orifices and across the free span between the shield and the parapet roof (slot). These flows attempt to detach the boundary layer with vortices generation (jet flow around) with a geometrical scale similar to the hole and slot dimension i.e. $2.5 \mathrm{~mm}$ and $0.82 \mathrm{~m}$ respectively.

The frequency of shedding of the vortices and its sound intensity level will depend on the wind speed.

The resistance to the flow through the holes is slightly higher compared to that presented for the slot. For example, for a value of average wind speed of about $20 \mathrm{~m} / \mathrm{s}$, the air velocity in the slot is about $16 \mathrm{~m} / \mathrm{s}$, while it is about $12 \mathrm{~m} / \mathrm{s}$ in the holes. In this case, the flow of vortices around the slot would present a frequency of $19 \mathrm{~Hz}$, while vortices emitted by the holes would have a frequency about $4800 \mathrm{~Hz}$. Each hole is assumed to be an acoustic transmitter on this frequency.

The characteristic frequencies and sound pressure levels for an average wind speed of $20 \mathrm{~m} / \mathrm{s}$ at the building height, for each one of the major characterized emitters are presented in Table 1.

\section{Field Measurements}

For sound pressure levels (SPL) characterization, three long-term continuous monitoring campaigns were performed on the roof. Additionally, other manual measurements of sound pressure levels and velocity measurements at the site were taken, to characterize the possible sound sources, and registered events of interest (see Table 2). For the identification of the events to be studied, it was assumed that the occurrence of sound events was linked to high wind velocity events simultaneously occurring with complaints about noise annoyance from people who work in the tower or from inhabitants of the close neighborhood.

Table 1. Characteristics of major acoustic sources.

\begin{tabular}{|c|c|c|}
\hline Issuer & Frequency (Hz) & $\mathrm{L}(\mathrm{dBZ})$ \\
\hline Flow around the building & 1 & - \\
\hline Support tubes & 35 & 74.0 \\
\hline Vibration plate & 177 & 44.0 \\
\hline Flow through the slot & 19 & - \\
\hline Flow through the holes & 4800 & 83.4 \\
\hline
\end{tabular}

Table 2. Measurements of sound pressure levels taken at the study site.

\begin{tabular}{cc}
\hline Noise Measurements & Duration \\
Long term measurements & 11 days \\
M1-first monitoring & 9 days \\
M2-second monitoring & 17 days \\
M3-third Monitoring & 4 hours \\
Short term measurements & 2 hours \\
MP1—characterization of sound sources, environmental measurements & \\
\hline
\end{tabular}

${ }^{1}$ Fields of pressures would be established on the building for various wind directions were derived from testing in small scale model made in the wind tunnel of the faculty of engineering [1]. 
Four main measuring points were established on the roof of the building, thus covering four areas defined by their geometry, Figure 3.

Continuous measurements for long-term SPL were taken with a sound meter Casella CEL 633-C, Class 1 according to IEC 61672. The instrument was located at point 4 on all three occasions (M1, M2, and M3). For short-term manual noise measurements (MP1 and MP2) a B\&K 2250 sound level meter, Class 1 according to IEC 61672 was used. Both instruments have current calibration and certification by traceable laboratory according to international standards.

For analyze events of interest, wind data registered from National Ports Administration (ANP, for its acronym in Spanish), were used. ANP monitors wind speed and direction each 1 minute. The anemometer is located $30 \mathrm{~m}$ over the level of the ground and a distance of $6.5 \mathrm{~km}$ to the WEST of building site.

On the other hand, for the analysis of wind climate in the studied area, a historical data series of hourly average wind speeds from Carrasco Weather Station was used. Carrasco Station has an anemometer installed at $10 \mathrm{~m}$ relative to the ground elevation. It is located about $12 \mathrm{~km}$ to the NORTHEAST of the point of interest.

In a complementary way, and in a particular case, wind measurements in the study site were made with a portable Anemometer Extech brand, model EN300.

\section{Noise}

Based on the whole information obtained from long- and short-term measurements of SPL, sound emission events associated with wind-induced flow through the facade of the building, were identified for the studying period.

The following information is summarized in Table 3:

-The time of occurrence of the event of interest;

-The frequency of identified pure tones and their sound pressure level relative to the average SPL of both lateral third-octave bands;

-The speed and wind direction at the height of the roof, assuming that it is the cause of noise emissions.

As it can be seen in Table 3, wind noise emissions were associated with a strong high-pitched sound which is perceived as a ringing on the roof. It is a strong pure tone at frequencies identified as belonging to the $4000 \mathrm{~Hz}$ octave-band [8]. Note that the superelevation of these tones is $17 \mathrm{dBZ}$ above the sound pressure levels on their sidebands in 6 of the 27 events identified and in all but one case are greater than $10 \mathrm{dBZ}$. Sound pressure levels exceeding $90 \mathrm{dBZ}$ were measured on the roof. These emissions would cause annoyance, because they would be perceived as annoying as broadband sound of (LA + 6) dBA [9] intensity because of their frequency and intensity (LA is intended to be the sound pressure level of the real broadband sound).

\section{Features of the Events of Interest}

\section{From short-term measurements}

During the performance of MP2, the occurrence of sound events that could be potential causes of annoyance was verified. Sound emissions were detected when the wind speed at the rooftop was expected to exceed from

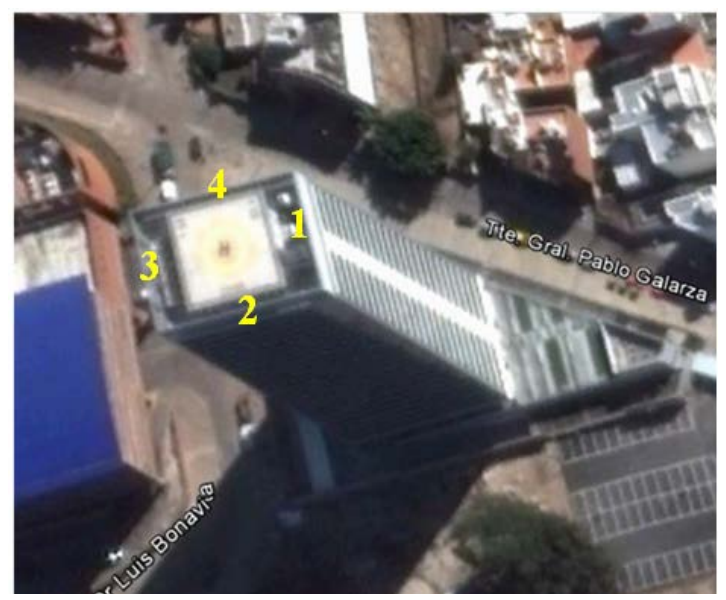

Figure 3. Points of sound measurements in the roof. 
Table 3. Events of interest identified on the building roof.

\begin{tabular}{|c|c|c|c|c|c|c|}
\hline \multirow{2}{*}{ Measurement } & \multirow{2}{*}{ Time } & \multirow{2}{*}{$\begin{array}{c}\text { Frequency } \\
\text { Pure Tone } \\
(\mathrm{Hz})\end{array}$} & \multicolumn{2}{|c|}{ Sound Pressure Levels } & \multicolumn{2}{|c|}{ Wind $^{\mathrm{a}}$} \\
\hline & & & Pure Tone (dBZ) & Superelevation of the Tone (dBZ) & Speed (m/s) & Direction \\
\hline MP2 & 3:58:49 PM & 5000 & 86.5 & 12 & 19.0 & WSW \\
\hline M2-day 1 & 3:41:00 PM & 3200 & 92.0 & 17 & 19.5 & $\mathrm{NE}$ \\
\hline M2-day 1 & 3:49:00 PM & 3200 & 91.4 & 16 & 16.0 & ENE \\
\hline M2-day 1 & 3:54:00 PM & 3200 & 80.7 & 12 & 17.8 & ENE \\
\hline M2-day 6 & 11:28:00 PM & 3200 & 87.4 & 14 & 32.3 & ESE \\
\hline M2-day 6 & 11:29:00 PM & 3200 & 85.1 & 13 & 32.3 & ESE \\
\hline M2-day 6 & 11:32:00 PM & 3200 & 83.9 & 13 & 18.0 & ESE \\
\hline M2-day 6 & 11:41:00 PM & 3200 & 84.7 & 11 & 19.5 & ESE \\
\hline M2-day 7 & 5:20:00 AM & 3200 & 88.3 & 16 & 29.1 & SSE \\
\hline M2-day 7 & 5:21:00 AM & 3200 & 85.2 & 16 & 29.1 & SSE \\
\hline M2-day 7 & 5:26:00 AM & 3200 & 87.9 & 16 & 20.8 & $S$ \\
\hline M2-day 7 & 5:27:00 AM & 3200 & 90.0 & 17 & 29.1 & SSE \\
\hline M2-day 7 & 5:28:00 AM & 3200 & 88.1 & 16 & 25.1 & SSE \\
\hline M2-day 7 & 5:31:00 AM & 3200 & 80.2 & 14 & 22.0 & $\mathrm{~S}$ \\
\hline M2-day 7 & 5:32:00 AM & 3200 & 85.6 & 15 & 30.4 & SSE \\
\hline M2-day 7 & 5:34:00 AM & 3200 & 92.0 & 17 & 25.1 & SSE \\
\hline M2-day 7 & 5:35:00 AM & 3200 & 86.2 & 16 & 16.0 & SSE \\
\hline M2-day 7 & 5:37:00 AM & 3200 & 84 & 15 & 26.4 & SSE \\
\hline M2-day 7 & 5:39:00 AM & 3200 & 85.2 & 16 & 22.0 & SSE \\
\hline M2-day 7 & 5:40:00 AM & 4000 & 88.4 & 4 & 30.4 & SSE \\
\hline M2-day 7 & 5:41:00 AM & 3200 & 86.5 & 16 & 20.8 & SSE \\
\hline M2-day 7 & 5:46:00 AM & 3200 & 84.5 & 16 & 34.7 & SSE \\
\hline M2-day 7 & 6:00:00 AM & 3200 & 81.8 & 15 & 27.6 & SSE \\
\hline M2-day 7 & 6:27:00 AM & 3200 & 85.5 & 15 & 26.4 & SSE \\
\hline M2-day 7 & 6:28:00 AM & 3200 & 89.8 & 17 & 27.6 & SSE \\
\hline M2-day 7 & 6:29:00 AM & 3200 & 92.3 & 17 & 23.6 & SSE \\
\hline M2-day 7 & 6:30:00 AM & 3200 & 91.2 & 17 & 27.6 & SSE \\
\hline M2-day 7 & 6:31:00 AM & 3200 & 81.1 & 14 & 26.4 & SSE \\
\hline
\end{tabular}

$16 \mathrm{~m} / \mathrm{s}$, blowing from WEST-SOUTHWEST direction. The flow through the perforated plate was the cause of the measured sounds.

In Figure 4 the features of one of the studied events are presented. It was identified at the SPL time evolution for a 16 minutes sample (Figure 4(a)). The spectral composition of a one minute sample of noise including the signal of interest is shown at Figure 4(b).

\section{From long-term measurements}

The spectra of some studied events are presented in Table 3. They are also graphically described in Figure 5.

The spectra of the analyzed events have a similar shape: they have lower intensities on low frequencies, then a 

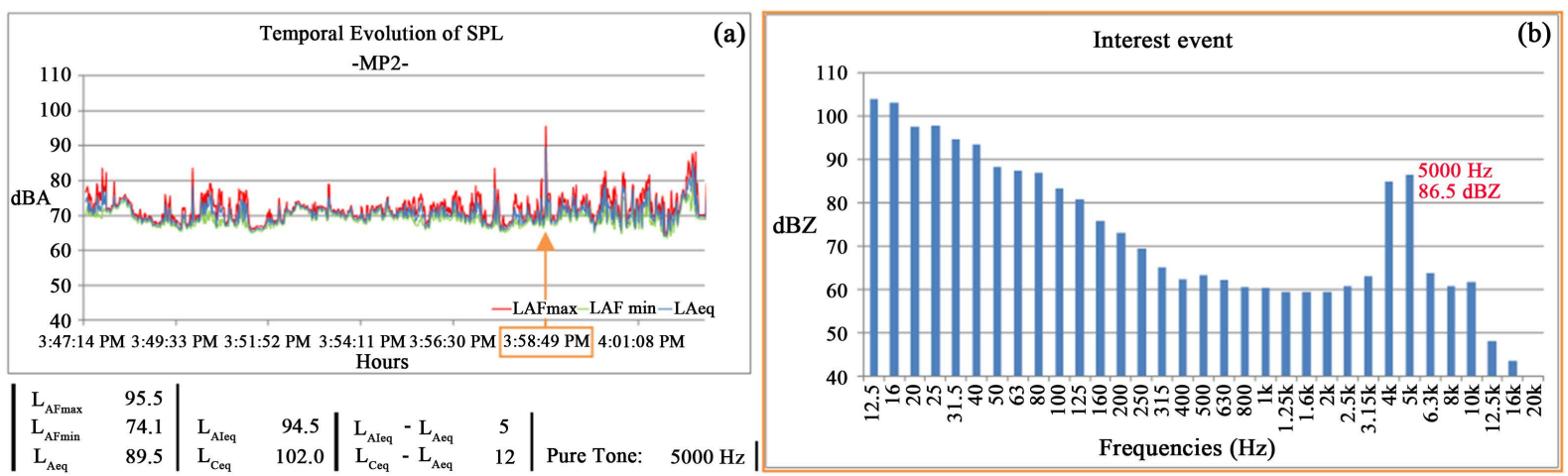

Figure 4. Description of the event of interest measured. (a) Evolution of SPL; (b) Spectral composition.
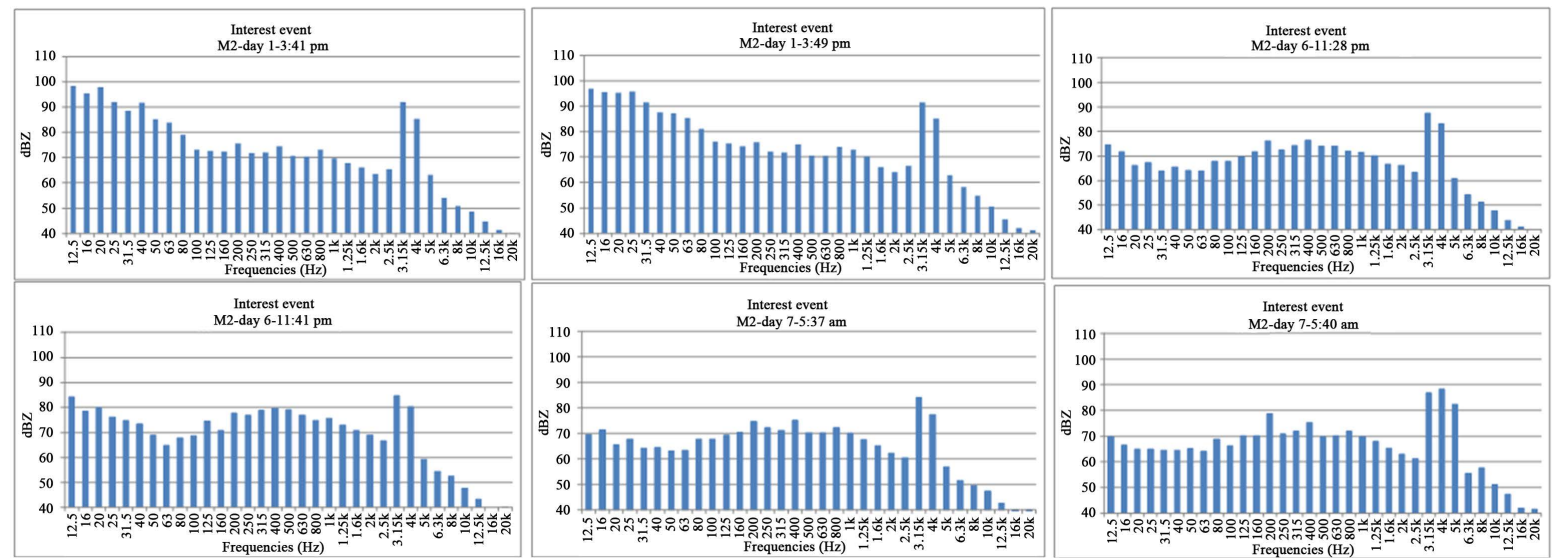

Figure 5. Spectral composition measured SPL event interest.

peak in midrange and another lower zone towards the high frequencies region where the above mentioned pure tones [8] can be found.

\section{Wind Tunnel Test}

In order to verify the behavior of the perforated plate as an acoustic source, a test was conducted in a wind tunnel of the faculty of engineering, UdelaR. At its entrance a flow straightener honeycomb consisting of hexagonal cross-section tubes of $26 \mathrm{~mm}$ side and a free passing area of $86.2 \%$ of the total area is located. To represent the shield under study, a perforated plate was placed $1.31 \mathrm{~m}$ downstream of the entrance of the tunnel. In Figure 6 a sketch of that wind tunnel and your work area is shown.

SPL measurements with two Class 1 sound level meters were performed simultaneously both inside and outside of the tunnel. A sound level meter B\&K 2250 was located in the center of the straight section, $3.43 \mathrm{~m}$ downstream of the entrance of the tunnel, and another Class 1 sound level meter Casella CEL-633C was installed out of the wind tunnel, $2 \mathrm{~m}$ downstream of its exit. The air velocity close to the microphone of the sound level meter outside the wind tunnel was measured with a handheld anemometer Extech EN300.

Two tests were carried out in two different working conditions. In the initial one, called basic condition, the test was conducted without the perforated plate, to determine the base noise. In the second condition the plate is installed. For each operating condition of the fan and for each test situation, the frequency of the identified pure tone and its sound pressure level measured inside the wind tunnel, in dBZ, are presented in Table 4.

The longitudinal turbulence intensity current above the shield was $2 \%$, whereas the longitudinal integral scale of the turbulence was $5 \mathrm{~mm}$ [1].

For each speed of the wind tunnel fan, the speed of the air flow through the orifices and the value of the characteristic frequency of the acoustic emission were estimated, as shown in Table 5. Note that the obtained frequency values are similar to those determined at the field measurements (Table 4). Table 5 presents an estima- 


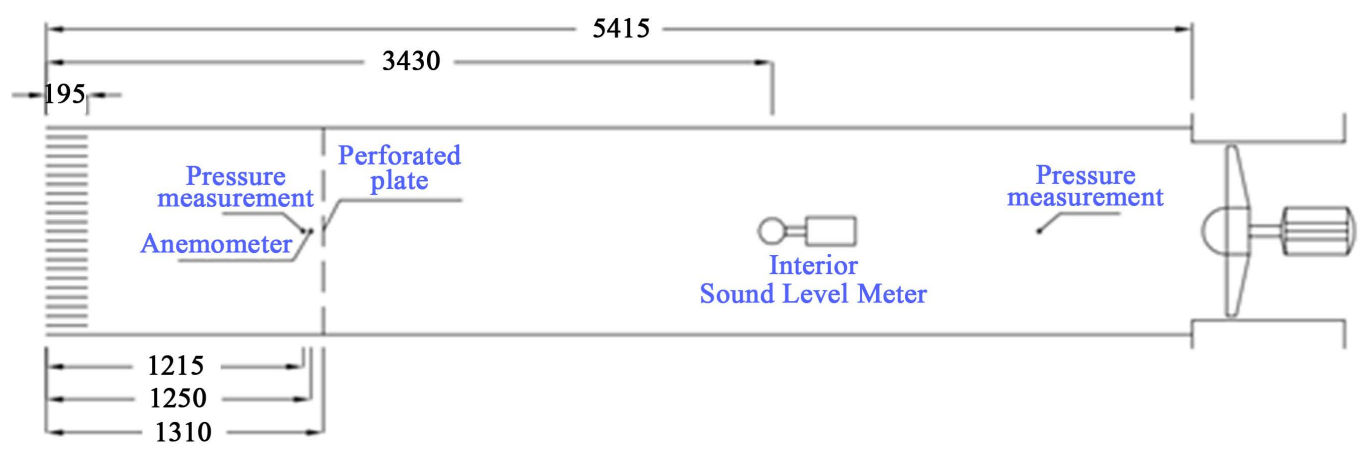

Figure 6. Sketch of wind tunnel.

Table 4. Frequency of pure tones for different fan rotation speeds.

\begin{tabular}{ccccc}
\hline \multirow{2}{*}{$\begin{array}{c}\text { Imposed frequency regulator } \\
\text { frequency (Hz) }\end{array}$} & $\begin{array}{c}\text { Speed fan } \\
(\mathrm{RPM})\end{array}$ & $\begin{array}{c}\text { Pure tone frequency } \\
(\mathrm{Hz})\end{array}$ & 2000 & \multicolumn{2}{c}{$\mathrm{L}(\mathrm{dBZ})$} \\
\cline { 4 - 5 } 30 & 600 & 2500 & 79.8 & Base noise $^{\text {Perforated plate }^{\mathrm{a}}}$ \\
\hline 40 & 800 & 3150 & - & 64.6 \\
50 & 1000 & 4000 & 89.4 & 69.0 \\
60 & 1200 & 5000 & 93.5 & 71.3 \\
70 & 1400 & 6300 & 96.7 & 72.3 \\
\hline
\end{tabular}

${ }^{\mathrm{a}}$ The energy associated with the base condition has just been subtracted in the informed levels.

Table 5. Frequency deduced from the air speed in hole.

\begin{tabular}{cccc}
\hline Imposed frequency regulator frequency $(\mathrm{Hz})$ & $\mathrm{V}_{\text {hole }}(\mathrm{m} / \mathrm{s})$ & Frequency $(\mathrm{Hz})$ & $\mathrm{L}(\mathrm{dBZ})$ \\
\hline 30 & 7.6 & 3030 & 77.8 \\
40 & 9.9 & 3957 & 81.7 \\
50 & 12.1 & 4838 & 86.6 \\
60 & 14.3 & 5723 & 89.1 \\
\hline
\end{tabular}

tion of the sound intensity level, assuming that each hole can be intended as an acoustic monopole, as it was done to obtain the values presented at Table 1.

Even if the estimated sound pressure levels are higher than measured ones, they follow a similar pattern (Table 5). Levels increase when so does the velocity of the air flow through the holes; this was also observed in some of the measurements in the wind tunnel.

Taking into account the theoretical developments presented, the results of field and wind tunnel measurements, it should be inferred that acoustic emissions on the roof of the building are due to the wind flow through the holes in the perforated plate installed as a shield over the building.

To evaluate the impact of the phenomenon on the surrounding population, the wind climate was analyzed. Then, improvement options were identified.

\section{Analysis Climate of Wind in the Area of the Building}

The time period in which the Carrasco weather station information is available, after elimination of "gaps" of data as well as the periods of time that this station does not operate, corresponds to a time series of velocity and 
wind direction with duration equivalent to eight years. Based on the characteristics of the land surrounding the building and the weather station, a time series of hourly speed and wind direction data at the site of implantation of the building at the height of its roof was inferred.

As it is noted above, it is verified that for the generation of pure tones at frequencies of interest, due to vortex shedding from the holes in the perforated plate (Table 3), the occurrence of weather events with wind speed over $16 \mathrm{~m} / \mathrm{s}$ is required at the level of the roof of the building (88 m high). The occurrence of weather events with wind speed greater than $16 \mathrm{~m} / \mathrm{s}$ at $88 \mathrm{~m}$ on the site of implantation of the building under consideration was analyzed. Especially, we considered those winds with mean velocity exceeding $20 \mathrm{~m} / \mathrm{s}$. Figure 7 shows that the wind roses for the study area are presented.

In Figure 7(a) the complete time series is considered while in Figure 7(b) only event with mean wind velocity of $20 \mathrm{~m} / \mathrm{s}$ is included. The events considered would give rise to the events that could potentially lead to acoustic emissions in octave band of $4000 \mathrm{~Hz}$. The data graphed in Figure 7(b) are presented in Table 6.

The total amount of these events would be around $0.96 \%$, equivalent to about an average of seven monthly events. Higher probability of occurrence of these winds can be seen to winds from SOUTH and SOUTHSOUTHWEST directions, meaning $54 \%$ of possible cases of interest.

It is assumed that the building of $120 \mathrm{~m}$ high, located towards SOUTHWEST-SOUTH-SOUTHWEST from the tower under study, protects it from the winds blowing from these directions, so the total number of events with the potential to cause discomfort will be $0.70 \%$, which is equivalent to an average of 5 events per month or one per week.

If the shield was protected by installing a polycarbonate sheet, it would be possible to avoid the wind flow through their holes. If this protection was installed on the facades oriented towards the SOUTH and WEST, it would be possible prevent $96.3 \%$ of noise events.

The analysis of acoustic emissions generated by the interaction between the wind and the facade of a building has been presented. The occurrence of certain weather events generated noise emissions from such intensity perceived and might result in a potential cause of discomfort events interest.

From the theoretical developments presented and the results of field and wind tunnel measurements, we can infer that these acoustic emissions are generated by vortex shedding through the holes in the perforated plate installed due to flow winds exceeding speed of $20 \mathrm{~m} / \mathrm{s}$, at the height of the roof of the building ( $88 \mathrm{~m}$ high). These results are also associated with noise nuisance complaints made by the people who live and/or work in the study area.

Under these conditions, the characteristics of the sound spectra of the events of interest indicate a similar behavior, presenting strong pure tones in the octave band of $4000 \mathrm{~Hz}$, which are perceived as a high-pitched sound
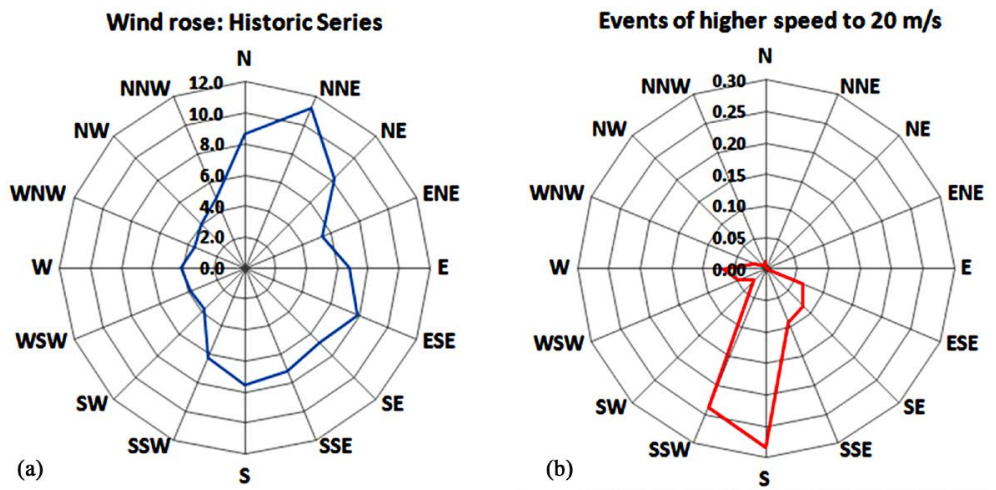

Figure 7. (a) Wind rose for relative frequencies of directions; (b) Wind rose to relative frequencies of direction and hourly average speeds above $20 \mathrm{~m} / \mathrm{s}$ (both on the roof of the building).

Table 6. Percentage of time exceeding $20 \mathrm{~m} / \mathrm{s}$ speed (also see Figure 7 (b)).

\begin{tabular}{|c|c|c|c|c|c|c|c|c|c|c|c|c|c|c|c|}
\hline $\mathrm{N}$ & NNE & $\mathrm{NE}$ & ENE & $\mathrm{E}$ & ESE & SE & SSE & $\mathrm{S}$ & SSW & SW & WSW & W & WNW & NW & NNW \\
\hline 0.012 & 0.002 & 0.001 & 0.004 & 0.001 & 0.063 & 0.084 & 0.093 & 0.283 & 0.238 & 0.026 & 0.047 & 0.067 & 0.021 & 0.009 & 0.006 \\
\hline
\end{tabular}


in the roof of the building and may cause feeling of annoyance because of their frequency and intensity to generate a similar perception of a broadband sound of (LA + 6) dBA [9], where LA is the sound pressure level of the broadband sound that has effectively occurred.

According to the analysis of winds for weather events that could potentially lead to event of annoyance associated to sound emissions, an average of 5 to 7 events per month would be registered. In order to mitigate these noise emissions, the installation of a polycarbonate shield on the existing metal shield on the facade of the building to avoid the wind flow through their holes could be proposed. If the shield is initially installed on the facades that are oriented towards SOUTH and WEST directions, the potentially annoying noise events would reduce $96.3 \%$.

\section{References}

[1] Cataldo, J., Lisboa, M. and González, E. (2012) Análisis de emisiones acústicas en el edificio World Trade Center Free Zone. Facultad de Ingeniería, UdelaR. Montevideo, Uruguay.

[2] Simiu, E. and Scanlan, R.H. (1986) Wind Effects on Structures: An Introduction to Wind Engineering. John Wiley \& Sons, Hoboken.

[3] Cataldo, J., et al. (2000) Programa de Evaluación de Calidad del Aire aplicado a la República Oriental del Uruguay. Informe Final, Convenio MVOTMA-UROU (Facultad de Ingeniería).

[4] Holmes, J. (2007) Wind Loading Structures. 2nd Edition, Taylor and Francis, UK.

[5] Blevins, R.D. (2003) Applied Fluid Dynamics Handbook. Krieger Pub Co., Malabar.

[6] Ahlborn, B., Seto, M. and Noack, B. (2002) On Drag, Strouhal Number and Vortex-Street Structure. Fluid Dynamics Research, 30, 379-399. http://dx.doi.org/10.1016/S0169-5983(02)00062-X

[7] Abreu, J., Guarga, R. and Izquierdo, J. (1995) Oscilaciones hidráulicas en sistemas hidroeléctricos. Capítulo 14 en Transitorios y oscilaciones en sistemas hidráulicos a presión. Valencia, España.

[8] Crocker, M. (2007) Handbook of Noise and Vibration Control. John Wiley \& Sons, Hoboken.

[9] ISO (2007) Acoustics. Description, Measurement and Assessment of Environmental Noise. Part 2: Determination of Environmental Noise Levels. ISO 1996-2:2007. 